\title{
A FORGOTTEN POINT OF VIEW IN THE TREATMENT OF MASSIVE BLEEDING? ECONOMIC STUDY ON HEMOTHERAPY ABOUT 1:1:1 PROTOCOL BASED ON CLINICAL AND ANALYTICAL CRITERIA VS HEMOTHERAPY GUIDED BY \\ MASIMO RADICAL® + ROTEM® MONITORING IN MASSIVE BLEEDING CASUALTIES. SPANISH MILITARY MEDICINE EXPERIENCE.
}

Ricardo Navarro Suay, Alberto Hernández-Abadía de Barbará, Antonio Pérez-Ferrer, Edurne López Soberón, Ramón Puchades Rincón de Arellano, Begoña González Marcos. Hospital Central de la Defensa "Gómez Ulla", Madrid (Spain) / Instituto Mixto de Investigación Biosanitaria de la Defensa -IMIDEF. Madrid (Spain)

\section{BACKGROUND AND GOAL OF THE STUDY}

Treating a patient with massive bleeding is a challenge for the anesthesiologist, who is responsible for assessing the epidemiology, physiology, clinical, treatment, monitoring and prognosis of these patients. However, the economic criteria are not always adequately known. In the recent conflicts in Iraq and Afghanistan, Military Medicine has implemented new protocols (some based on high ratios of units of packed red blood cells, fresh frozen plasma units and platelet units) and new monitors as Rotem $®$ or Massimo ${ }^{\circledR}$ in order to improve battle casualties care.

The goal of this study is to analyze cost-benefit of treatment according to protocol 1:1:1 (1 unit of packed red blood cells: 1 unit of fresh frozen plasma: 1 unit of platelets) vs guided therapy goals with monitoring devices Masimo Radical 7 / Rotem in patients with massive bleeding in military environment.

\section{MATERIAL AND METHODS}

We performed a cost-benefit analysis of two treatments used in massive bleeding patients. We employ a model with a time horizon of seven years, based on data collected in the Spanish Military Hospital in Herat (Afghanistan).

Because there are various prices in the market, we have selected the official cost of blood products published by the Ministry of Defense of Spain, and the cost of different monitors was provided by commercial agents in contact to the Ministry of Defense (Spain).

The combat casualty data were obtained from the record of Spanish Military Hospital in Herat (Afghanistan). The data sent and blood products consumed throughout the study period has been provided by the Transfusion Centre of the Armed Forces and the service laboratory and clinical analysis of the Spanish Military Hospital in Herat. They have achieved the appropriate permissions to obtain such information. It has been used based Excel (Microsoft $\circledast$ ) data for data processing.
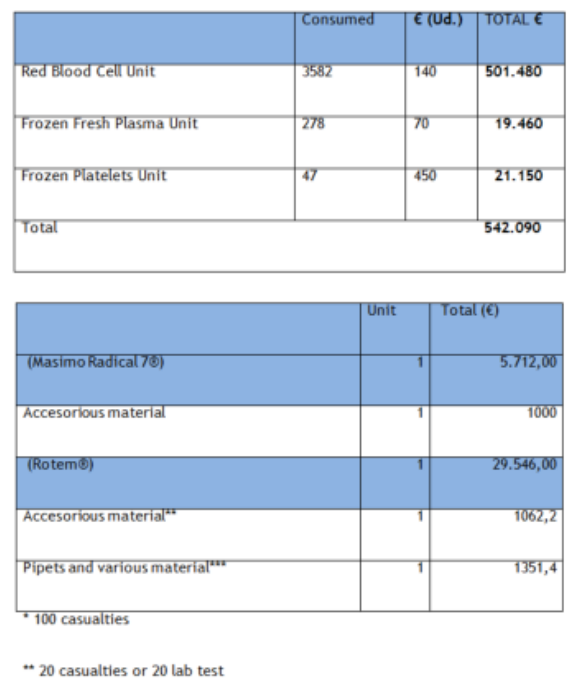

RESULTS

During the study period, 3582 units of packed red blood cells $(15.7 \%, 565$ consumed), 278 units of fresh frozen plasma $(66 \%, 184$ consumed) and 47 units of frozen platelets (31\%, 21 consumed) were sent to Afghanistan. The cost of blood products was 1 unit of packed red blood cells: $140 €, 1$ unit of fresh frozen plasma: $7 €, 1$ unit of frozen platelets: $450 €$. The cost of blood products shipped (+ not consumed) was $542,090 €(101,430 €+440,660 €)$.

The price offered by commercial agents was Masimo. Radical $\circledast$ 7: 5,712€ and consumables (100 patients): 1,000€ while Rotem $\AA$ device was 29,546€, consumables (20 measurements): $1062 €$ and disposables and pipettes (200 measurements): $1,351 €$.

The number of casualties with massive bleeding was 36 .

According to several studies the Monitor Masimo reduces by $47 \%$ the units of packed red blood cells and monitor Rotem reduces $84 \%$ units of fresh frozen plasma and $41 \%$ platelet units.

It is assumed as the $80 / 20$ rule hypothesis: patients with massive bleeding have required $80 \%$ of total consumption. A half-life of the monitors 10 years is assumed for wear material. Therapy 1:1:1 could be started since 2010 (not before the lack of logistical capacity).

The cost of blood units consumed in massive bleeding casualties was 55,950€, while ROTEM and Masimo monitors (monitors + consumables + units of blood) cost was $€ 57,455$.

The total cost of blood units not consumed was $294,570 €$, however total cost of blood units not employed with two monitors and ensuring logistical support was $€ 103,740$.

\section{CONCLUSION}

Guided therapy by Masimo Radical 7 + Rotem devices is $2,7 \%$ more expensive than 1:1:1 treatment in massive bleeding casualties. However, cost of blood products units shipped and not used $(294,570 €)$, compared to units shipped and not used employing both monitors $(103,740 €)$ is higher $(190,830 €)$ 